\title{
Highly Copper(II) Ion-selective Transport through Liquid Membrane Containing 1-(2-Pyridylazo)-2-naphthol
}

\author{
Morteza AKHOND ${ }^{\dagger}$ and Mozhgan BAGHERI \\ Department of Chemistry, Faculty of Sciences, Shiraz University, Shiraz, Iran
}

(Received February 5, 2002; Accepted May 22, 2002)

The separation of chemical species from a complex mixture is often an important process in industry and chemical analysis. Liquid-membrane transport in which the extraction and stripping operations are combined in a single process reduces the solvent inventory requirement, and also allows the use of expensive and highly selective extractions, which otherwise would be uneconomic in solvent extractants. For these reasons, liquid-membrane transport has attracted worldwide attention, and much work has been directed toward developing methods for its application to the separation of various metal ions. ${ }^{1-12}$

Proton-driven cation transport through a liquid membrane containing an ion-selective ionophore bearing a protondissociable moiety is one of the most effective separation techniques for a particular metal ion. ${ }^{13-16}$ In this membrane cation transport system, there is no need for the counter anion to counterbalance the positive charge, because the protondissociated ionophore, itself, acts as the counter anion of the complexing cation. Therefore, the cation transport ability is independent of the extent of hydrogen of a counter anion. Uphill transport against a cation concentration gradient is also feasible, since cations are transferred by the counter transport of protons.

Different methods for the specific transport of $\mathrm{Cu}(\mathrm{II})$ ions across a liquid membrane have been reported which have drawbacks of a slow rate for transport or a lack of high selectivity. ${ }^{17-22}$ For example, it has been reported that $N, N^{\prime}$ bis(8-quinolyl)glutaramide can selectivily and effectively transport copper ion (63\%) through a choloroform membrane after 2 days. ${ }^{20}$

Therefore, the development of effective and specific systems for studying the transport of metal ions, particularly $\mathrm{Cu}(\mathrm{II})$, is a remarkable task from both practical and theoretical viewpoints.

1-(2-Pyridylazo)-2-naphthol (PAN) is a dye, which tends to form a complex with some metal ions. It is used as a photometric reagent (with or without extraction) for a wide variety of metal ions and as a metal indicator in chelatometric titration. To the best of our knowledge, no work on the use of PAN as a carrier in transport systems has been reported previously. In this paper we report that PAN is an excellent carrier for the high selectivity, rapid and uphill transport of $\mathrm{Cu}(\mathrm{II})$ ions through a liquid membrane.

\footnotetext{
$\dagger$ To whom correspondence should be addressed

E-mail: akhond@chem.susc.ac.ir
}

\section{Experimental}

Reagents

PAN was purchased from Merck chemical company and used as received. Reagent-grade chloroform (Fluka) was used as a membrane organic solvent. A stock solution of copper $(1.26 \times$ $10^{-2} \mathrm{~mol} / \mathrm{L}$ ) was prepared by dissolving an appropriate amount of $\mathrm{Cu}\left(\mathrm{NO}_{3}\right)_{2} \cdot 3 \mathrm{H}_{2} \mathrm{O}$ (Fluka) in a $1000 \mathrm{~mL}$ calibrated flask and diluting to the mark with triply distilled water. The solution was standardized iodometrically. ${ }^{23}$ Working solutions were prepared by suitable dilution of the stock solution. All other chemicals used in this study were of the highest purity available from either Merck or Fluka chemical companies and used without further purification. Triply distilled deionized water was used throughout.

\section{Apparatus}

A bulk-type liquid membrane cell (Fig. 1) was used. The atomic-absorption spectrophotometer used for measuring the metal ion concentration was a Philips Pye Unicam SP9 instrument. $\mathrm{pH}$ measurements were made with a Corning 125 pH-meter using a combined glass electrode.

\section{Procedure}

All transport experiments were done at ambient temperature. For transporting a cation, such as $\mathrm{Cu}^{2+}$, across a liquid membrane, a bulk-type liquid membrane cell was used in this study (Fig. 1).

A cylindrical glass cell (inside diameter of $4.0 \mathrm{~cm}$ ) holding a glass tube (inside diameter of $2.0 \mathrm{~cm}$ ), for separating the two aqueous phases, was used. The membrane phase in which the carrier was dissolved, lied below two aqueous phases, and

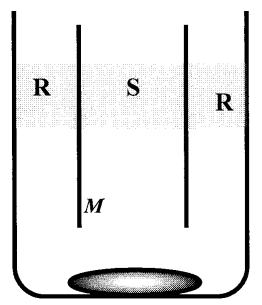

Fig. 1 Liquid-membrane apparatus (S, source phase; R, receiving phase; $\mathrm{M}$, liquid membrane). 
bridged them. The inner aqueous phase (source phase) contained copper nitrate $\left(5 \mathrm{~mL}, 1.26 \times 10^{-4} \mathrm{~mol} / \mathrm{L}\right)$, which was adjusted to $\mathrm{pH} 7.0$ with an ammonium buffer. The outer aqueous phase (receiving phase) contained sulfosalicylic acid (10 mL, $0.05 \mathrm{~mol} / \mathrm{L})$.

A chloroform solution $(25 \mathrm{~mL})$ containing $1 \times 10^{-3} \mathrm{~mol} / \mathrm{L}$ PAN was used as a liquid-membrane phase. The organic layer was slowly stirred by a Teflon-coated magnetic bar $(3 \mathrm{~mm} \times 5$ $\mathrm{mm}$ diameter). The cell was covered with an aluminum foil to minimize solvent evaporation. After allowing a period of time, the metal ion concentrations of both aqueous phases were measured by atomic-absorption spectroscopy along with a series of standard solutions which were made similarly, in order to convert the atomic-absorption signals to concentration units. The reproducibility was obtained as $2.2 \%$. A similar experiment was carried out in the absence of a carrier for a reference. The detailed conditions are included in the tables.

\section{Results and Discussion}

The dye PAN was introduced by $\mathrm{Liu}^{24}$ and $\mathrm{Bray}^{25}$ to the analytical field. This ligand has been used almost exclusively as a metallochromic indicator and as an extractive chelating agent for spectrophotometric and colorimetric determinations of submilligram amounts of metals. Although this reagent, itself, is rather unselective, by choosing the $\mathrm{pH}$ and masking reagent it is possible to attain selectivity. ${ }^{26}$ Preliminary experiments showed that PAN reacts slowly with some metal ions. For example, it was investigated that the PAN chelate of cobalt is not formed at a sufficient rate at any $\mathrm{pH}$. Because copper is one of the metal ions that reacts quickly with PAN, ${ }^{27}$ copper(II) was chosen for this study for two reasons: selectivity and rate of extraction. In this study, we described the transport of copper(II) in a bulk liquid membrane using PAN as a carrier.

\section{Effect of the $\mathrm{pH}$ of the source phase}

The effect of the $\mathrm{pH}$ of the source phase on the efficiency of copper transport was investigated. The results revealed that the maximum copper transport occurs at $\mathrm{pH} 7-8$. At lower $\mathrm{pH}$ values there was a decrease in the percentage of copper(II) transport, probably due to a decrease of the ammonium concentration for exchanging a proton with $\mathrm{Cu}^{2+}$ at the interface of the source/membrane phases. The efficiency of transport decreases at higher $\mathrm{pH}$ values, probably due to the complex formation of copper(II) ion and ammonia.

\section{Effect of the concentration of ammonia solution in the source} phase

In order to investigate the effect of the concentration of ammonia solution for buffer preparation, different concentrations of ammonia solution (between $0-0.3 \mathrm{~mol} / \mathrm{L}$ ) in the source phase were used. The results show that the maximum transport occurred at a concentration of $0.1 \mathrm{~mol} / \mathrm{L}$ of ammonia in the source phase. For this reason, a $0.1 \mathrm{~mol} / \mathrm{L}$ ammonium concentration was selected for further studies.

\section{Effect of the PAN concentration in the organic phase}

In order to investigate the influence of the concentration of PAN in the organic phase on the transport efficiency of copper(II), different concentrations of PAN in the range of $0-2$ $\times 10^{-3} \mathrm{~mol} / \mathrm{L}$ in chloroform were used. According to the results, the percent transport of copper enhances with an increase in the carrier concentration in the organic phase. Maximum transport was occurred at a concentration of $1.0 \times 10^{-3} \mathrm{~mol} / \mathrm{L}$ of PAN.
Table 1 Effect of the presence of various compounds in receiving phase on transport efficiency of copper(II) ${ }^{\mathrm{a}}$

\begin{tabular}{lcc}
\hline \multicolumn{1}{c}{ Compound } & $\begin{array}{l}\text { Percentage transported } \\
\text { into receiving phase }\end{array}$ & $\begin{array}{l}\text { Percentage remaining } \\
\text { in source phase }\end{array}$ \\
\hline Sulfosalicylic acid & 98.2 & - b $^{\mathrm{b}}$ \\
L-Threonine & $-{ }^{\mathrm{b}}$ & 44.2 \\
L-Glycine & $-\mathrm{b}$ & 54.6 \\
L-Citrulline & $-{ }^{\mathrm{b}}$ & 52.4 \\
Potassium oxalate & - $^{\mathrm{b}}$ & 47.9 \\
DL-Alanine & - $^{\mathrm{b}}$ & 40.1 \\
\hline
\end{tabular}

a. Experimental conditions: source phase, $5 \mathrm{~mL}$ of $1.26 \times 10^{-4} \mathrm{~mol} / \mathrm{L}$ $\mathrm{Cu}^{2+}$ and $0.1 \mathrm{~mol} / \mathrm{L}$ ammonia $(\mathrm{pH}=7.0)$; liquid membrane phase, 25 $\mathrm{mL}$ of $1 \times 10^{-3} \mathrm{~mol} / \mathrm{L}$ PAN in chloroform; receiving phase, $10 \mathrm{~mL}$ of $0.05 \mathrm{~mol} / \mathrm{L}$ of various compounds; time of transport, $100 \mathrm{~min}$.

b. Cannot be detected.

Thus, $1 \times 10^{-3} \mathrm{~mol} / \mathrm{L}$ was chosen as the optimum concentration for further studies. Meanwhile, no transport of any metal ions occurred in the absence of an ionophore. Thus, it is evident that the concentration of PAN is important in determining the transport rate of copper from the source phase into the receiving phase.

Effect of the nature of the stripping agent on the transport efficiency of copper(II)

The transport of copper(II) in the presence of different compounds in the receiving phase was studied; results are given in Table 1. As can be seen, the nature and composition of the receiving phase were found to have a significant influence on the copper(II) ion transport. The maximum transport occurred when sulfosalisylic acid was added in the receiving phase as a stripping agent for copper(II).

Regarding the fact that this transport is proton-driven, we had to make sure that sulfosalicylic acid is the best stripping agent for copper(II) transport. Therefore, the $\mathrm{pH}$ of all other compounds that were added in the receiving phase as stripping agents was adjusted by nitric acid to reach the $\mathrm{pH}$ of the sulfosalicylic acid solution. The experiment was then again performed under new conditions. It was found that although the tested stripping reagents, such as L-threonine and L-glycine, could strip copper from the membrane under the new $\mathrm{pH}$ condition, however the rate of transport was highest when sulfosalicylic acid was used as the stripping agent. Thus, sulfosalicylic acid was selected for further studies.

\section{Effect of the sulfosalicylic acid concentration in the receiving phase}

The effect of the sulfosalicylic acid concentration in the range of $0.001-0.1 \mathrm{~mol} / \mathrm{L}$ in the receiving phase was also investigated. The results show that an increase in the sulfosalicylic acid concentration of up to $0.05 \mathrm{~mol} / \mathrm{L}$ increases the efficiency of copper(II) transport. A further increase in the sulfosalicylic acid concentration did not improve the efficiency of copper(II) transport. For this reason, $0.05 \mathrm{~mol} / \mathrm{L}$ of the sulfosalicylic acid concentration was selected for further studies.

\section{Effect of time}

Figure 2 shows the time dependence of copper(II) transport through the liquid membrane under the optimum experimental conditions. It is obvious that, an increase in time increased the percentage transport of copper(II) to the receiving phase, and decreased the percentage of copper(II) remaining in the source phase for up to $100 \mathrm{~min}$. After this time, the concentrations of 


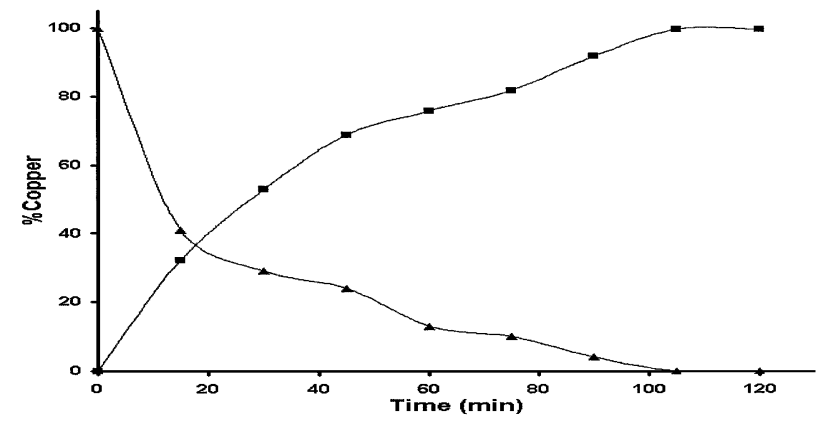

Fig. 2 Percentage of $\mathrm{Cu}^{2+} v$ s. time in the source $(\boldsymbol{\Delta})$ and receiving phases ( $\mathbf{\square})$.

copper(II) in the aqueous phases were independent of time and the transport was completed $(100 \%)$.

\section{Reproducibility of bulk liquid membrane}

The reproducibility of copper transport was investigated and the percent of metal ion transported after 100 min obtained from ten replicate measurements was found to be $96.2 \pm 2.2 \%$.

\section{Selectivity of the system}

In order to investigate the selectivity of the above system for the transport of copper(II) over other cations, equimolar mixtures of copper ion and some other cations were placed in the source phase. Then transport of these mixtures was investigated under $\mathrm{pH} 7$ and 8 for the source phase, regarding the fact that the optimum $\mathrm{pH}$ for source phase was $7-8$ (Table 2). A comparison of the results in the table depicts that the efficiency of copper(II) transport at $\mathrm{pH} 7$ is less than $\mathrm{pH} 8$. However, with regard to the result that all the metal ions used as interference at $\mathrm{pH} 7$ remain in the source phase more than at $\mathrm{pH}$ 8 , and that none of them enters into the receiving phase at $\mathrm{pH} 7$, the selectivity of this system at $\mathrm{pH} 7$ is more than at $\mathrm{pH} 8$. Thus, these results signify the fact that the selectivity of this system depends on the type of stripping agent and the selection of an appropriate $\mathrm{pH}$ for the source phase.

\section{Suggested mechanism}

In order to suggest a mechanism for the transport of copper(II), the $\mathrm{pH}$ values of the source and receiving phases were measured before and after copper(II) transport. The increase in the $\mathrm{pH}$ of source phase and the decrease of the $\mathrm{pH}$ of receiving phase prove that the mechanism is proton-driven. That is, the transport phenomenon is based on a deprotonationprotonation cycle of PAN in the membrane interfaces of the source and the receiving phases, respectively. The copper(II) ion forms a complex with a proton-dissociated ionophore $\left(\mathrm{PAN}^{-}\right)$to be extracted from the source phase into the membrane phase. In the interface between the membrane and the receiving phase, the copper complex of PAN should be protonated and release copper into the receiving phase; then, the protonated ionophore would be transferred through the membrane phase to the interface of the source phase.

\section{Conclusions}

A transport system for copper(II) ion through a bulk-liquid membrane system containing PAN as a carrier was studied. It was found that PAN is an excellent carrier for the selective and efficient transport of copper(II). This high selectivity is due to
Table 2 Transport efficiency of copper(II) in the presence of foreign ions at $\mathrm{pH}=7$ and $\mathrm{pH}=8$ of source phase ${ }^{\mathrm{a}}$

\begin{tabular}{|c|c|c|c|c|}
\hline \multirow{2}{*}{ Mixture } & \multicolumn{2}{|c|}{$\begin{array}{l}\text { Percentage transported } \\
\text { into receiving phase }\end{array}$} & \multicolumn{2}{|c|}{$\begin{array}{l}\text { Percentage remaining } \\
\text { in source phase }\end{array}$} \\
\hline & $\mathrm{pH}=7$ & $\mathrm{pH}=8$ & $\mathrm{pH}=7$ & $\mathrm{pH}=8$ \\
\hline \multicolumn{5}{|l|}{ Mixture 1: } \\
\hline $\mathrm{Cu}^{2+}$ & 94.1 & 98.1 & 6.2 & $-^{\mathrm{b}}$ \\
\hline $\mathrm{Ni}^{2+}$ & $-^{b}$ & $-^{b}$ & 98.1 & 95.2 \\
\hline \multicolumn{5}{|l|}{ Mixture 2: } \\
\hline $\mathrm{Cu}^{2+}$ & 91.3 & 100 & 7.4 & $-^{\mathrm{b}}$ \\
\hline $\mathrm{Co}^{2+}$ & $-^{\mathrm{b}}$ & $-^{\mathrm{b}}$ & 100 & 100 \\
\hline \multicolumn{5}{|l|}{ Mixture 3: } \\
\hline $\mathrm{Cu}^{2+}$ & 82.3 & 100 & 10.1 & $-^{\mathrm{b}}$ \\
\hline $\mathrm{Mn}^{2+}$ & $-^{\mathrm{b}}$ & $-^{\mathrm{b}}$ & 94.4 & 95.5 \\
\hline \multicolumn{5}{|l|}{ Mixture 4: } \\
\hline $\mathrm{Cu}^{2+}$ & 89.5 & 93.1 & 5.3 & 3.3 \\
\hline $\mathrm{Zn}^{2+}$ & $-^{\mathrm{b}}$ & 9.2 & 100 & 94.2 \\
\hline \multicolumn{5}{|l|}{ Mixture 5: } \\
\hline $\mathrm{Cu}^{2+}$ & 94.5 & 100 & 6.4 & $-^{\mathrm{b}}$ \\
\hline $\mathrm{Cd}^{2+}$ & $-^{\mathrm{b}}$ & 8.2 & 93.2 & 93.8 \\
\hline \multicolumn{5}{|l|}{ Mixture 6: } \\
\hline $\mathrm{Cu}^{2+}$ & 86.2 & 100 & 12.3 & $-^{b}$ \\
\hline $\mathrm{Mg}^{2+}$ & $-^{\mathrm{b}}$ & $-^{\mathrm{b}}$ & 100 & 100 \\
\hline \multicolumn{5}{|l|}{ Mixture 7: } \\
\hline $\mathrm{Cu}^{2+}$ & 62.2 & 87.5 & 26.1 & 2.6 \\
\hline $\mathrm{Pb}^{2+}$ & $-^{b}$ & 0.5 & 100 & 20.3 \\
\hline \multicolumn{5}{|l|}{ Mixture 8: } \\
\hline $\mathrm{Cu}^{2+}$ & 100 & 100 & $-^{\mathrm{b}}$ & $-^{\mathrm{b}}$ \\
\hline $\mathrm{Hg}^{2+}$ & 8.3 & 8.1 & 90.1 & 90.2 \\
\hline \multicolumn{5}{|l|}{ Mixture 9: } \\
\hline $\mathrm{Cu}^{2+}$ & 97.4 & 96.2 & $-^{\mathrm{b}}$ & $-^{\mathrm{b}}$ \\
\hline $\mathrm{Ag}^{+}$ & $-^{\mathrm{b}}$ & $-^{\mathrm{b}}$ & 100 & 100 \\
\hline \multicolumn{5}{|l|}{ Mixture 10: } \\
\hline $\mathrm{Cu}^{2+}$ & 98.0 & 96.5 & 5.1 & $-^{\mathrm{b}}$ \\
\hline $\mathrm{Fe}^{2+}, \mathrm{Fe}^{3+}$ & $-^{c}$ & & & \\
\hline
\end{tabular}

a. Experimental conditions: source phase, $5 \mathrm{~mL}$ of $1.26 \times 10^{-4} \mathrm{~mol} / \mathrm{L}$ of each ions and $0.1 \mathrm{~mol} / \mathrm{L}$ ammonia; membrane phase, $25 \mathrm{~mL}$ of $1 \times$ $10^{-3} \mathrm{~mol} / \mathrm{L}$ PAN in chloroform; receiving phase, $10 \mathrm{~mL}$ of $0.05 \mathrm{~mol} / \mathrm{L}$ sulfosalicylic acid; time of transport, $100 \mathrm{~min}$.

b. Cannot be detected.

c. $\mathrm{Fe}^{2+}, \mathrm{Fe}^{3+}$ are in precipitate form under experimental conditions.

the fact that, at the $\mathrm{pH}$ chosen for the source phase, most of the ions mentioned react with PAN only slightly, or react with PAN much more slowly than does with copper. According to the literature, it may be expected that some of the metal ions that were not investigated, such as uranium(IV), thallium(III), indium, titanium and rare earths, will not interfere, because of partial extraction in the $\mathrm{pH}$ range used..$^{28-30}$

This study demonstrates the usefulness of the liquidmembrane technique for making it possible to combine extraction and stripping operations in a single process and reducing the solvent inventory requirements. In conclusion, therefore, the above system, which is highly selective for copper(II) is a potential candidate for practical use in copper separation. The system especially, has the advantages of low solvent requirement with high precision, efficiency and selectivity together with simplicity and speed.

\section{Acknowledgements}

The authors wish to express their gratitude to Shiraz University Research Council for the support of this work. 


\section{References}

1. T. Saito, Sep. Sci. Technol., 1993, 28, 1629.

2. R. M. Izatt, R. L. Bruening, W. Geng, M. H. Cho, and J. J. Christensen, Anal. Chem., 1987, 59, 2405.

3. M. Akhond and M. Shamsipur, J. Chin. Chem. Soc., 1996, 43, 225.

4. M. Shamsipur, G. Azimi, and S. S. Madaeni, J. Membr. Sci., 2000, 165, 217.

5. M. Akhond and M. Shamsipur, Sep. Sci. Technol., 1995 , 30,306

6. M. Akhond and M. Shamsipur, Bull. Chem. Soc. Jpn., 1997, 70, 339.

7. A. Safavi and E. Shams, J. Membr. Sci., 1999, 157, 171

8. M. Akhond and M. Shamsipur, J. Membr. Sci., 1996, 117, 221.

9. M. Akhond and M. Shamsipur, Sep. Sci. Technol., 1997, 32,1223

10. S. Dadfarnia and M. Shamsipur, Bull. Chem. Soc. Jpn., 1992, 65, 2779.

11. A. Safavi and S. Rastegarzadeh, Talanta, 1995, 42, 2039.

12. M. A. Chaudry, S. Amin, and M. T. Malik, Sep. Sci. Technol., 1996, 31, 1309.

13. P. R. Brown and R. A. Bartsch, in "Topics in Inclusion Science", Vol. 2, "Inclusion Aspects of Membrane Chemistry", ed. T. Osa, J. L. Atwood, and Kluwer, 1999, Dordrecht, 1 - 57.

14. J. Ishikawa, H. Sakamoto, and M. Otomo, Analyst, 1997,
122, 1383.

15. E. Kimura, C. A. Dalimunte, A. Yamashita, and R. Machida, J. Chem. Soc. Chem. Commun., 1985, 1041.

16. L. A. Ferderick, T. M. Fyles, V. A. Malik, and D. M. Whitfield, J. Chem. Soc. Chem. Commun., 1980, 1211.

17. K. Kubo, J. Kubo, C. Kaminaga, and T. Sakurai, Talanta, 1998, 45, 963.

18. K. Maruyama, H. Tsukube, and T. Araki, J. Chem. Soc. Dalton Trans., 1981, 1486.

19. N. Kishii, K. Araki, and S. Shiraishi, J. Chem. Soc. Dalton Trans., 1985, 373.

20. K. Hiratani and K. Taguchi, Chem. Lett., 1990, 725.

21. D. K. Schiffer, A. Hackhauser, D. F. Euans, and E. L. Cassler, Nature, 1974, 250, 484.

22. M. Dicasa, L. Fabbrizzi, A. Perotti, and P. Tundo, Inorg. Chem., 1985, 24, 1610.

23. A. I. Vogel, "A Text-Book of Quantitative Inorganic Analysis", 3rd ed., 1961, Longman, London, 952.

24. Ch. J. Liu, Ph. D. Thesis, University of Illinois, 1951.

25. K. L. Chang and R. H. Bray, Analyst, 1955, 27, 782.

26. S. Shibata, "Chelate in Analytical Chemistry", ed. M. Dekker, 1972, Vol. 3, New York.

27. A. Galik, Talanta, 1969, 16, 201.

28. J. Stary, "The Solvent Extraction of Metal Chelates", 2nd ed., 1966, Pergamon Press, Oxford, Mir, Moscow.

29. K. L. Cheng and B. L. Goydish, Anal. Chim. Acta, 1966, 34,154

30. A. Galik and M. Knizek, Talanta, 1966, 13, 1169. 